\title{
Differential protein expression between EBV-positive and negative epithelial cells
}

\author{
Haibo $\mathrm{Yu}^{1,2^{*}}$, Lian Zhao ${ }^{3^{*}}$, Qijia Yan ${ }^{1^{*}}$, Lielian $\mathrm{Zuo}^{1^{*}}$, Zhengyuan $\mathrm{Yu}^{1}$, Wei Xiong ${ }^{1}$, Xiaoling $\mathrm{Li}^{1}$, \\ Shourong Sheng ${ }^{3}$, Zhaojian Gong ${ }^{1}$, Jianhong $\mathrm{Lu}^{1 \#}$, Guiyuan $\mathrm{Li}^{1 *}$ \\ ${ }^{1}$ Cancer Research Institute, Central South University, Changsha, China; \\ \#Corresponding Author: jianhlu@csu.edu.cn, ligy@xysm.net \\ ${ }^{2}$ Institute of Metabolism and Endocrinology, The Second Xiangya Hospital and the Diabetes Center, Metabolic Syndrome Research \\ Center, Key laboratory of Diabetes Immunology, Ministry of Education, Central South University, Changsha, China \\ ${ }^{3}$ Department of Gastroenterology, Third Xiangya Hospital, Central South University, Changsha, China
}

Received 27 February 2013; revised 29 March 2013; accepted 7 April 2013

Copyright (C) 2013 Haibo Yu et al. This is an open access article distributed under the Creative Commons Attribution License, which permits unrestricted use, distribution, and reproduction in any medium, provided the original work is properly cited.

\begin{abstract}
Epstein Barr virus infection is believed to play a role in the development of nasopharyngeal carcinoma. In order to investigate the function of EBV in epithelial cell, proteomic methods were used to find and identify the differential proteins and expected to elucidate the mechanism of EBV. Altered protein expressions were found between 293 cell (HEK293) and EBV infected cell (293-EBV). In this study, we separated differential expressed proteins using 2D-DIGE method while matrix-assisted laser desorption/ionization tandem time of flight mass spectrometry (MALDI-TOF-MS) method was used to identify proteins. The results showed that 14 proteins were up regulated and 3 proteins were down regulated in 293-EBV cells. Bioinformatic analysis showed that these proteins are involved in cell proliferation, metastasis, apoptosis, metabolism, and signal transduction. Western blotting analysis was further carried out to verify the MS results. Thus, EBV may exert its functions by mediating differential expression of these proteins.
\end{abstract}

Keywords: EBV; Differential In-Gelelectrophoresis (DIGE); Mass Spectrometry

\section{INTRODUCTION}

Epstein Barr virus infection has been believed to play a key role in the development of many tumors such as

\footnotetext{
*These authors contributed equally to this work.

"Corresponding author.
}

nasopharyngeal carcinoma (NPC) which prevalently accrus in southern China and Southeast Asia. In our previous study, the proliferation rate of epithelial cell was faster after transfection with EBV genome. The growth of xenografts was also enhanced after the transfected cells were injected into nude mice in vivo. The mechanism of EBV is still unclear, thus in this work powerful proteomic technologies were used to elucidate the potential roles of EBV. As it is known, protein is the ultimate life performer. How does EBV regulate the protein profile of epithelial cell? Our study uses the differential in-gel electrophoresis DIGE and MALDI-TOF-MS (Matrix-assisted laser desorption/ionization time of flight mass spectrometry) to select and identify differential expressed protein compared 293 cells with 293-EBV cells. The results are analyzed to illuminate the mechanism of EBV in promoting cell proliferation and differentiation in protein level, which supply a new target and clue for cure and prognostic of EBV associated cancer.

\section{Materials and methods}

\subsection{Cell Types and Protein Preparation}

293 and The EBV-infected cell, 293-EBV, were preserved and propagated in our laboratory. They were cultured in DMEM medium (GIBCO) supplemented with $10 \%$ fetal bovine serum, $5 \% \mathrm{CO}_{2}$ atmosphere at $37^{\circ} \mathrm{C}$. Cells were collected during the exponential growth phase. DMEM (Dulbecco's Modified Eagle's medium) purchased from Hgclone company; 2D-Clean up protein purification kit and 2D-Quant Kit purchased from the Amersham Biosciences company. The cells were extracted with DIGE lysis buffer. After lysed for $40 \mathrm{~min}$ on ice, the supernatant was transferred into a new microcentrifuge tube. The concentration of protein was determined with 
Bio-Rad protein assay reagent.

\subsection{Two-Dimensional Fluorescence Difference Gel Electrophoresis (2D-DIGE)}

For two-dimensional fluorescence difference gel electrophoresis (2D-DIGE), the IPG-strip was re-hydrated with sample at $30 \mathrm{~V}$ for 12 hours, and then IEF was conducted at $500 \mathrm{~V}$ for 1 hour, $1000 \mathrm{~V}$ for 1 hour, $10,000 \mathrm{~V}$ for $8 \mathrm{~h}, 500 \mathrm{v}$ for $10 \mathrm{~h}$. After IEF, the strips were equilibrated in equilibration buffer Afterward, the IPG strips were electrophoresed on $12.5 \%$ acrylamide gels in the second dimension with electrophoresis parameter $3 \mathrm{w}$ per gel for $30 \mathrm{~min}$ then $16 \mathrm{w}$ per gel. The gels were scanned with a Typhoon 9400 fluorescence scanner (GE Healthcare). DeCyder 2D soft was used to match and select the different expressed proteins (folds $>1.8$ ). Then, preparation of gel to cut different expressed proteins and the different expressed proteins identified by MALDI-TOFMS/MS.

\subsection{Western Blotting}

Western blotting was carried out as described previously. Antibody to HSP-70, $\beta$-actin was purchased from Sigma-Aldrich (St Louis, MO).

\subsection{Statistical Analysis}

SPSS11.5 software was adopted to do student's t-test analysis. All data showed by $\mathrm{X} \pm \mathrm{S}$. $p<0.05$ means that the difference was statistically significant.

\section{Results}

\subsection{Protein Expression Profile in 293 and 293-EBV Cells}

We obtained the images of proteins from 293 cells, 293-EBV cells and from the internal standard using different emission filters on the Typhoon 9400 fluorescence scanner. The obtained images were analyzed by DeCyder 5.0 software. We compared the protein expression in each group, and the results of the matched spots from the different gels were analyzed by Student's t test. We found 17 protein spots which showed consistent expression differences (fold $>1.8$ ) between the two groups (Figure 1, Table 1). The differentially expressed proteins were selected and analyzed by the MALD I-TOF-MS/MS. The PMF are obtained and identified by FlexAnalysis 3.0 software from NCBInr data. Take the number of 1940 protein spot (Raichu404X) as an example showed in Figures 2-4. Raichu404X was up-regulated significantly in 293-EBV cell. To validate the results of MALDI-TOF/ MS/MS, two different expressed proteins are detected by western blot between 293 cell line and 293-EBV cell

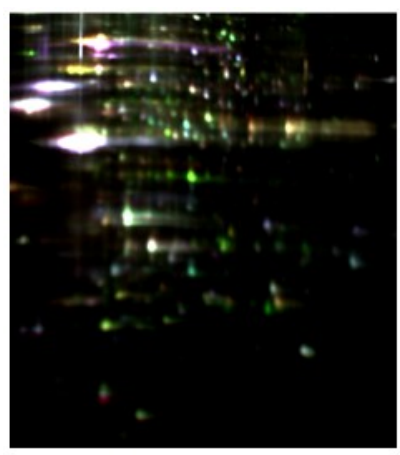

(a)

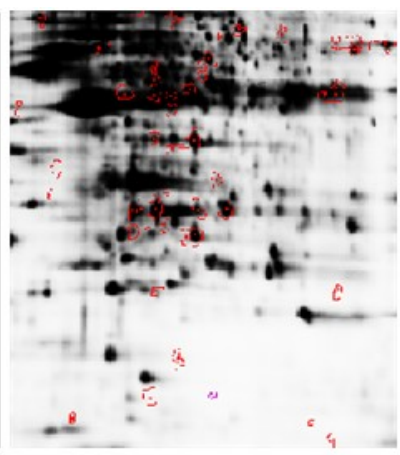

(b)
Figure 1. Overlapping image of three different emission filters. Red circles represent the differentially expressed proteins detected (a) separated proteins dye overlay with Cy2, Cy3, Cy5 (b) elected and labeled significant difference proteins.

(a)
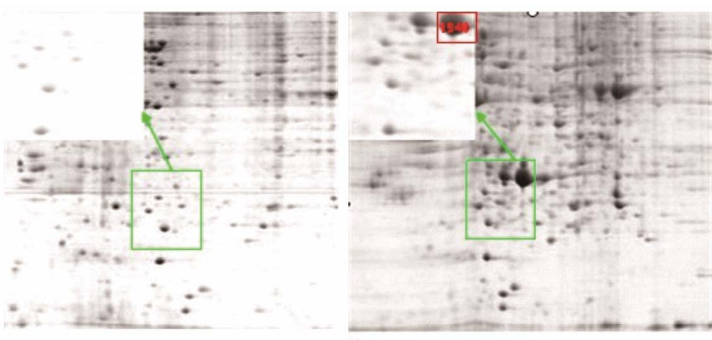

(b)

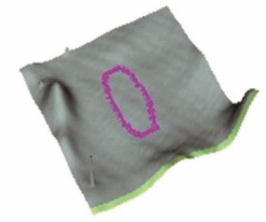

(A)

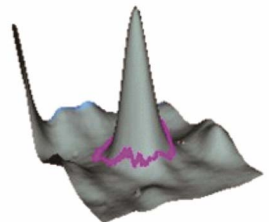

(B)
Figure 2. (A) Raichu404X (the spot number 1940) protein expression level in the 293 cell line (control). (B) Raichu404X protein expression level in the 293-EBV cell line. As a graphic showed, the spot 1940 field within the magnified boxes (topleft) was up-regulated in 293-EBV cell line; the same result was showed in b (three-dimension graphics).

line. The different expressed Raichu404X and Hsp70 protein were validated by Western blot. The results are consistent with results of MALD-I-TOF/MS/MSAs which it is known. Raichu404X and Hsp70 proteins are closely associated with carcinogenesis. They are involved in several biological functions including signal transduction, Cell migration, DNA synthesis, cell proliferation, cell apoptosis and invasion of many cancers.

\section{Discussion}

According to DIGE analysis, 14 up-regulated proteins and 3 down-regulated proteins in the 293-EBV, the differently expressed protein spots were chosen and identi- 
Table 1. The identified differentially expressed proteins between 293 and 293-EBV cells.

\begin{tabular}{|c|c|c|c|c|c|c|}
\hline Spot No. & Accession No. & Protein name & Level & Function & Fold & p-value \\
\hline 574 & gi|62896815 & $\begin{array}{l}\text { Heat shock } 70 \text { kDa protein } 8 \\
\text { isoform } 2 \text { variant }\end{array}$ & Up & Cellcycle, proliferation & 3.78 & 0.0018 \\
\hline 598 & gi|42543698 & $\begin{array}{c}\text { Chain A, the crystal structure of } \\
\text { the human Hsp70 Atpase } \\
\text { domain }\end{array}$ & Up & Cellcycle, proliferation & 3.546 & 0.0024 \\
\hline 701 & gi|83754516 & $\begin{array}{l}\text { Chain B, crystal structure of the } \\
\text { Chip-Ubc13-Uev1a complex }\end{array}$ & Up & Ubiquitylation & 2.83 & 0.0028 \\
\hline 760 & gi|4506753 & RuvB-like 1 & Up & Proliferation & 1.86 & 0.036 \\
\hline 853 & gi|119597640 & $\begin{array}{l}\text { Protein disulfide isomerase family } \\
\text { A, member 3, isoform CRA_a }\end{array}$ & Up & Metabolism & 1.85 & 0.021 \\
\hline 920 & gi|5453603 & $\begin{array}{c}\text { Chaperonin containing TCP1, } \\
\text { subunit } 2\end{array}$ & Down & Cellcyclecytoskeletal proteins & 1.89 & 0.00083 \\
\hline 1248 & gi|34234 & Laminin-binding protein & Up & Invasion and metastasis & 1.96 & 0.05 \\
\hline 1862 & gi|5668560 & $\begin{array}{l}\text { Serine/threonine phosphatase } 1 \\
\text { gamma }\end{array}$ & Up & Cellcycle, proliferation & 2.16 & 0.041 \\
\hline 1878 & gi|62324 & $\begin{array}{l}\text { Epstein-Barr nuclear antigen } \\
\text { [Human herpesvirus ] }\end{array}$ & Up & $\begin{array}{c}\text { Generegulation, } \\
\text { extrachromosomal replication }\end{array}$ & 6.51 & 0.00021 \\
\hline 1926 & gi|70995211 & $\begin{array}{l}\text { Peroxisomal enoyl-coenzyme A } \\
\text { hydratase-like protein }\end{array}$ & Up & $\begin{array}{l}\text { Metabolism the fatty acid } \\
\text { beta-oxidation pathway }\end{array}$ & 2.95 & 0.022 \\
\hline 1940 & gi|14595132 & Raichu404X [Homo sapiens] & Up & RAS signal pathway & 22.22 & $8.40 \mathrm{E}-05$ \\
\hline 1979 & gi|6755214 & Proteasome activator subunit 3 & Up & Cell cycle, proliferation & 2.14 & 0.0013 \\
\hline 2071 & gi|6912586 & 6 phosphogluconolactonase & Up & Metabolism & 2.46 & 0.017 \\
\hline 2081 & gi|5803013 & $\begin{array}{c}\text { Endoplasmic reticulum protein } 29 \\
\text { isoform } 1 \text { precursor [Homo } \\
\text { sapiens }\end{array}$ & Up & Stress & 8.13 & 0.00085 \\
\hline 2479 & gi|4758504 & $\begin{array}{c}\text { Hydroxysteroid (17-beta) } \\
\text { dehydrogenase } 10 \text { isoform } 1 \\
\text { [Homo sapiens] }\end{array}$ & Up & $\begin{array}{l}\text { Metabolism steroid hormones } \\
\text { and fats }\end{array}$ & 1.86 & 0.045 \\
\hline 3392 & gi|3891774 & $\begin{array}{c}\text { Crystal structure of a human low } \\
\text { molecular weight } \\
\text { phosphotyrosyl phosphatase }\end{array}$ & Down & Metabolism & 2.16 & 0.0056 \\
\hline 3600 & gi|4584423 & AKAP450 protein & Down & $\begin{array}{l}\text { Immunity/induce Tcell to } \\
\text { combine }\end{array}$ & 2.17 & 0.014 \\
\hline
\end{tabular}

fied as heat shock 70, Chip-Ubc13-Uev1a, RuvB-like 1, protein disulfide isomerase, TCP1, laminin-binding protein, serine/threonine phosphatase, Epstein-Barr nuclear antigen, peroxisomal enoyl-coenzyme A hydratase-like protein, Raichu404X, proteasome activator subunit 3, 6phosphogluconolactonase, endoplasmic reticulum protein 29 isoform 1 precursor, hydroxysteroid (17-beta) dehydrogenase 10 isoform 1, Human Low Molecular Weight Phosphotyrosyl Phosphatase and AKAP450 protein. The identified proteins involved in numerous crucial intracellular functions such as cell cycle and apoptosis, regulation of signal transduction pathways, cell proliferation and so on. Since it has been suggested that Raichu404X contains Ras interaction domain and that Cdc42Hs is a member in Ras/MAPK pathways Raichu404X is differently expressed in stem cells [1]. The function of Raichu404X needs further investigated. Hsp70 as central components of the cellular chaperone network, are frequently recruited by viruses and is important factors in developmental and pathological processes such as oncogenesis, neurodegenerative and autoimmune diseases, viral infections and aging [2-5]. Hsp70 interacts with key regulators of many signal transduction pathways controlling cell homeostasis, proliferation, differentiation and cell death and Hsp70 are ubiquitous molecular chaperones that function in a myriad of biological processes, modulating 

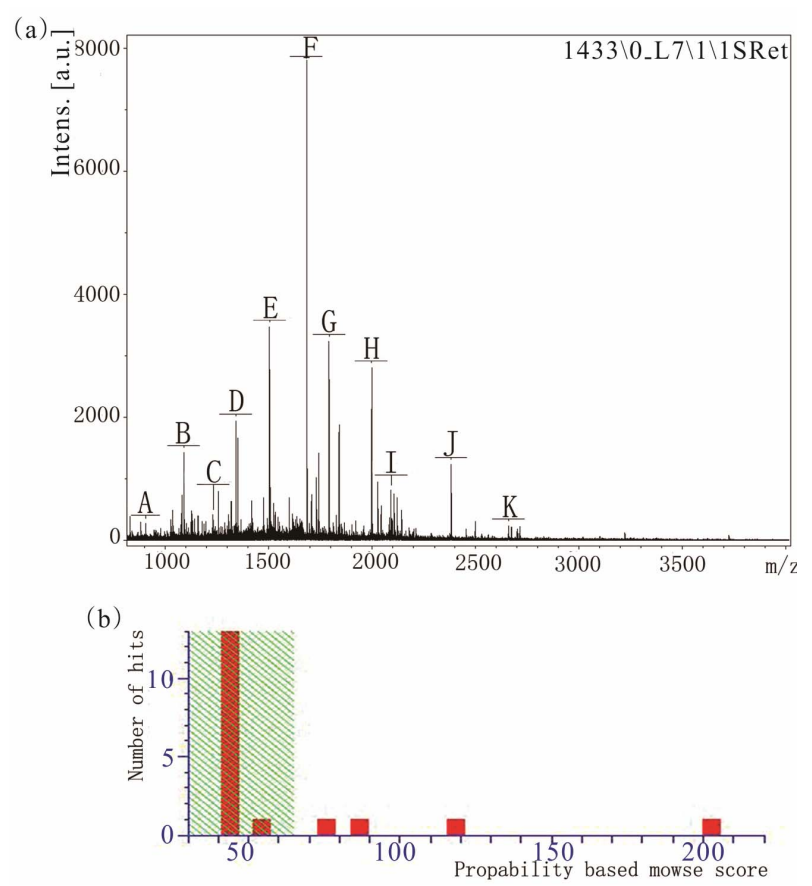

Figure 3. (a) Database searches of the masses of the trypsinized peptides identified the protein based on the 11 spikes from A to K. (b) Mass spectrometric characterization of Raichu404X.

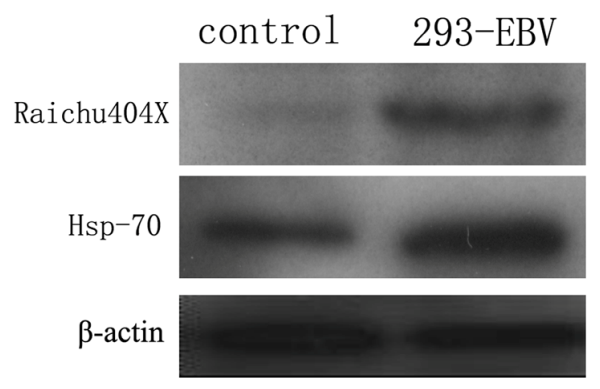

Figure 4. Westernblot results show the Raichu404X and Hsp70 proteins are up-regulated in 293-EBV cell line. (A) Control (293) (B) 29 3-EBV.

polypeptide folding, degradation and translocation across membranes, and protein-protein interactions [6-10]. Hsp70 and other members of the Hsp family have been shown to inhibit apoptosis at several different stages [7,9]. This work will provide us significant clue to clarify the happen of EBV associated diseases and new molecular will be used for prognosis and drug targets of clinic.

\section{ACKNOWLEDGEMENTS}

This work was supported by Projects of Hunan Provincial Natural Science Foundation of China (11JJ2043), the National Natural Science Foundation of China (81171931), the Research and Development Pro- ject of Hunan Development and Reform Commission (2009-13910), Graduate Degree Thesis Innovation Foundation of Central South University (2010ybfz102), Doctor Innovation Research Project of Hunan Province (CX2010B040).

\section{REFERENCES}

[1] Zou, J., Yu, X., Bao, Z. and Dong, J. (2011) Proteome of human colon cancer stem cells: A comparative analysis. World Journal of Gastroenterology, 17, 1276-1285. doi:10.3748/wjg.v17.i10.1276

[2] Beere, H.M., Wolf, B.B., Cain, K., Mosser, D.D., Mahboubi, A., Kuwana, T., Tailor, P., Morimoto, R.I., Cohen, G.M. and Green, D.R. (2000) Heat-shock protein 70 inhibits apoptosis by preventing recruitment of procaspase- 9 to the Apaf-1 apoptosome. Nature Cell Biology, 2, 469475. doi:10.1038/35019501

[3] Jolly, C. and Morimoto, R.I. (2000) Role of the heat shock response and molecular chaperones in oncogenesis and cell death. Journal of National Cancer Institute, 92, 1564-1572.

[4] Millar, D.G., Garza, K.M., Odermatt, B., Elford, A.R., Ono, N., Li, Z. and Ohashi, P. (2003) Hsp70 promotes antigenpresenting cell function and converts T-cell tolerance to autoimmunity in vivo. National Medicine, 9, 1469-1476. doi:10.1038/nm962

[5] Mayer, M.P. (2005) Recruitment of Hsp70 chaperones: A crucial part of viral survival strategies. Reviews of Physiology, Biochemistry \& Pharmacology, 153, 1-46. doi:10.1007/s10254-004-0025-5

[6] Kregel, K.C. (2002) Heat shock proteins: Modifying factors in physiological stress responses and acquired thermotolerance. Journal of Applied Physiology, 92, 21772186.

[7] Kampinga, H.H. and Craig, E.A. (2010) The HSP70 chaperone machinery: J proteins as drivers of functional specificity. Nature Reviews Molecular Cell Biology, 11, 579592. doi:10.1038/nrm2941

[8] Rérole, A.L., Gobbo, J., Thonel, A.D., Schmitt, E., Barros, J.P., Hammann, A., Lanneau, D., Fourmaux, E., Deminov, O., Micheau, O., Lagrost, L., Colas, P., Kroemer, G. and Garrido, C. (2011) Peptides and Aptamers Targeting HSP70: A Novel Approach for Anticancer Chemotherapy. Cancer Research, 71, 484-495. doi:10.1158/0008-5472.CAN-10-1443

[9] Walsh, N., Larkin, A., Swan, N., Conlon, K., Dowling, P., McDermott, R. and Clynes, M. (2011) RNAi knockdown of Hop (Hsp70/Hsp90 organising protein) decreases invasion via MMP-2 down regulation. Cancer Letters, 306, 180-189. doi:10.1016/j.canlet.2011.03.004

[10] Jiang, B., Liang, P.F., Deng, G.H., Tu, Z.Z., Liu M.D. and Xiao, X.Z. (2010) Increased stability of Bcl-2 in HSP70mediated protection against apoptosis induced by oxidative stress. Cell Stress and Chaperones, 16, 143-152. 